\title{
Papers
}

\section{False positive staining in the TUNEL assay to detect apoptosis in liver and intestine is caused by endogenous nucleases and inhibited by diethyl pyrocarbonate}

\author{
B J Stähelin, U Marti, M Solioz, H Zimmermann, J Reichen
}

\begin{abstract}
Background-The terminal transferase uridyl nick end labelling (TUNEL) assay allows the easy demonstration of cell death as a result of apoptosis. However, when this assay is applied to liver tissue, the number of TUNEL positive cells is dependent on the time of incubation with proteinase $\mathrm{K}$.

Aim-To test whether false positive results are the result of the release of endogenous endonucleases by proteinase $K$ and can be abolished by pretreatment with diethyl pyrocarbonate (DEPC).

Methods-Involution of hyperplastic ductules in bile duct ligated rats after biliary decompression by Roux-en-Y anastomosis and acute $\mathrm{CCl}_{4}$ intoxication were studied as models of apoptosis and necrosis, respectively. A standard TUNEL assay was applied to formalin fixed tissue sections mounted with cement. To inhibit putative endogenous endonucleases, tissue slides were pre-incubated with DEPC. Results-In the standard TUNEL assay, the number of positive nuclei was highly dependent upon the length of time that sections were incubated with proteinase K. After pretreatment with DEPC, only cells that also exhibited morphological features of apoptosis stained positive. DEPC pretreatment abolished false positive staining in $\mathbf{C C l}_{4}$ induced hepatocyte necrosis and blocked interference by endogenous alkaline phosphatase in intestine. The method of gluing the tissue section to the glass slide was found to be of utmost importance because the effect of DEPC was abolished on silanised slides. Conclusions-False positive staining in the TUNEL assay in the liver is caused by the release of endogenous endonucleases as a result of proteinase treatment. This can be abolished by pretreatment of tissue slides with DEPC.

(F Clin Pathol: Mol Pathol 1998;51:204-208)
\end{abstract}

Keywords: immunohistochemistry; in situ nick end labelling; apoptosis; liver
Apoptosis is an important mechanism in the regulation of tissue homeostasis and, in the liver, it is an important feature of different pathological conditions. ${ }^{1}$ An important method for visualising apoptotic cells is the terminal transferase uridyl nick end labelling (TUNEL) method, described by Gavrieli et al, ${ }^{2}$ although this method fails to discriminate between apoptosis and necrosis. ${ }^{3}$

Bile duct ligation induces marked proliferation of ductular epithelial cells ${ }^{45}$ and these hyperplastic ductules regress rapidly after biliary decompression by Roux-en-Y biliary anastomosis. ${ }^{6}$ Morphologically, this can be seen to be the result of apoptosis. ${ }^{7}$ We were interested in applying the TUNEL assay to measure apoptosis after biliary decompression but found an undue dependence of the number of apoptotic cells on the time of incubation with proteinase $\mathrm{K}$, a step required to render the nuclear DNA fragments accessible to the terminal transferase. We hypothesised that this phenomenon was the result of DNA nicking by endogenous endonucleases set free by the proteinase $\mathrm{K}$ treatment.

\section{Materials and methods}

\section{ANIMAL TREATMENT}

Male Sprague-Dawley rats were obtained from Süddeutsche Versuchstierfarm Hartmut and Voss (Tuttlingen, Germany) and were kept under a 12 hour light-dark cycle with free access to standard rat feed and tap water. Biliary cirrhosis was induced by bile duct ligation and dissection according to Kontouras et $a l,{ }^{4}$ as described previously by our laboratories. ${ }^{5}$ Biliary decompression was performed by a Roux-en-Y biliodigestive anastomosis as described previously. ${ }^{6}$ To induce acute hepatocyte necrosis, $\mathrm{CCl}_{4}$ was given by gavage $\left(\mathrm{CCl}_{4}\right.$ in corn oil $(1 / 4 \mathrm{vol} / \mathrm{vol}) 2 \mathrm{ml} / \mathrm{kg}$ of body weight); studies were performed 24 hours after intoxication. ${ }^{3}$ All animal experiments had been approved by the State Board on Ethics in Animal Experimentation following strict international guidelines.

Organs (liver, thymus, and intestine) were obtained under phenobarbital anaesthesia ( $50 \mathrm{mg} / \mathrm{kg}$ intraperitoneally) and were immer-
Accepted for publication 21 April 1998 

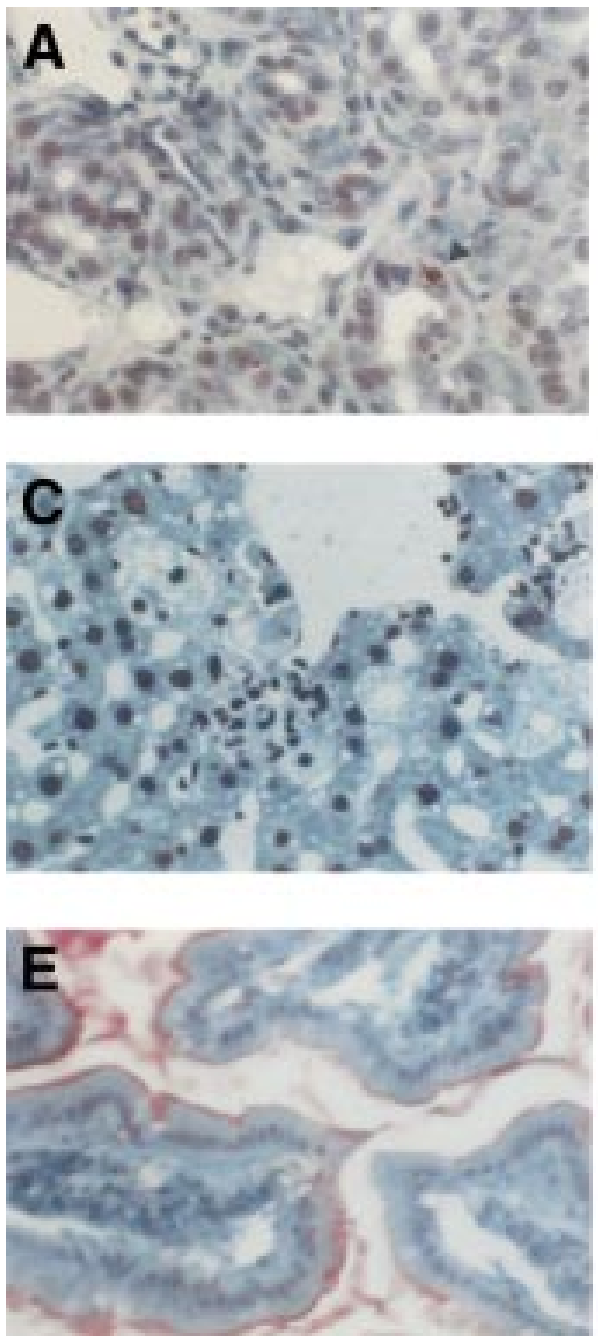
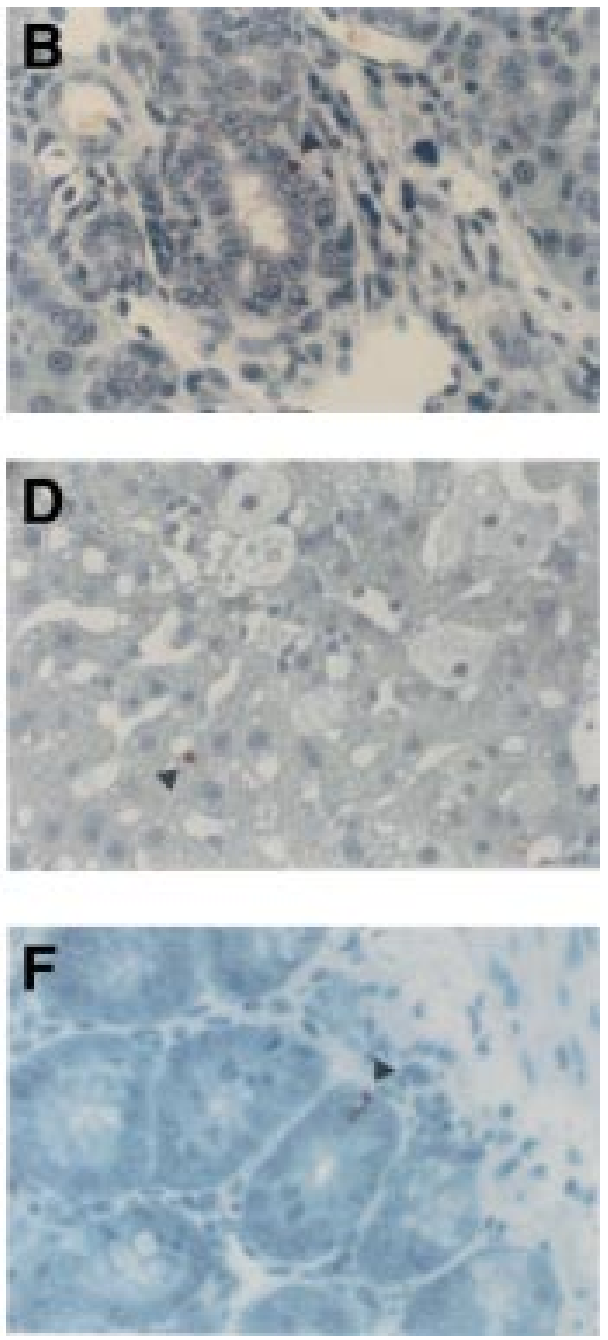

Figure 1 Results of the TUNEL assay in different tissues; all slides are counterstained with haematoxylin and shown at a final magnification of $\times 250$. (A) Standard TUNEL assay in liver after 45 minutes of proteinase K pretreatment showing an obvious false positive reaction in up to $75 \%$ of all nuclei. (B) After DEPC pretreatment only cells meeting the morphological criteria of apoptosis stained positive. (C) Detection of DNA fragmentation by the standard TUNEL assay in liver tissue slides 24 hours after $\mathrm{CCl}_{4}$ intoxication demonstrating false positive staining in ballooned hepatocytes and in apparently normal hepatocytes. (D) In the modified TUNEL assay, this false positive staining is abolished by DEPC pretreatment. (E) TUNEL assay in intestine without DEPC pretreatment. Endogenous alkaline phosphatase activity is seen along the apical section of the epithelial cell lining; furthermore, the nuclei also show some false positive staining. (F) After DEPC pretreatment, the endogenous alkaline phosphatase is inhibited completely and no false positive staining of nuclei occurs.

sion fixed immediately in buffered formaldehyde ( $4 \% \mathrm{vol} / \mathrm{vol})$. Liver tissue was subjected to systematic random sampling ${ }^{8}$ for stereological analysis, as described previously. ${ }^{5}$ After dehydration, tissues were embedded in paraffin wax and cut into $4-6 \mu \mathrm{m}$ sections.

TUNEL ASSAY

The assay was performed as described by Gavrieli et al. ${ }^{2}$ The paraffin sections were stuck on to glass slides with cement (Cementit weiss, $5 \%$ in distilled water; Merz and Benteli SA, Niederwangen, Switzerland), dewaxed with xylene, and rehydrated through a series of decreasing concentrations of ethanol. Next, the slides were partially digested with proteinase $\mathrm{K}(10 \mu \mathrm{g} / \mathrm{ml}$; Boehringer Mannheim, Mannheim, Germany) in Tris/ $\mathrm{HCl}$ buffer (20 mmol/l, pH 8.1) containing EDTA $(5 \mathrm{mmol} / \mathrm{l})$ at $37^{\circ} \mathrm{C}$ for up to 60 minutes; digestion was stopped with $\mathrm{H}_{2} \mathrm{O}$ and the slides were washed four times in distilled water.
Thereafter, the sections were incubated for 90 minutes at $37^{\circ} \mathrm{C}$ with terminal deoxyribonucleotidyl transferase $(75 \mathrm{U} / \mathrm{ml})$ and digoxigenin11-dUTP $(5 \mathrm{nmol} / \mathrm{ml})$ in potassium cacodylate buffer $(200 \mathrm{mmol} / \mathrm{l} ; \mathrm{pH} 8.0)$ containing serum bovine albumin $(50 \mu \mathrm{g} / \mathrm{ml})$ and $\mathrm{CoCl}_{2}$ $(2.5 \mathrm{mmol} / \mathrm{l})$. After 90 minutes, the slides were washed with SSC buffer $(150 \mathrm{mmol} / 1 \mathrm{NaCl}$, $15 \mathrm{mmol} / \mathrm{l}$ sodium citrate, $\mathrm{pH} 7.0$ ), followed by Tris/ $\mathrm{HCl}(10 \mathrm{mmol} / \mathrm{l}, \mathrm{pH} 8.2)$ in $150 \mathrm{mmol} / 1$ $\mathrm{NaCl}$. Non-specific binding was blocked with the blocking reagent from Boehringer Mannheim (for nucleic acid hybridisation and detection) for 30 minutes at room temperature. Labelled nick ends of DNA strands were visualised with the alkaline phosphatase reaction, using Fab fragments against digoxigenin linked to alkaline phosphatase, and fast red chromogen as a substrate (Boehringer Mannheim). The reaction was stopped after 15-30 minutes by washing with $\mathrm{H}_{2} \mathrm{O}$. Slides were counterstained lightly with haematoxylin. 


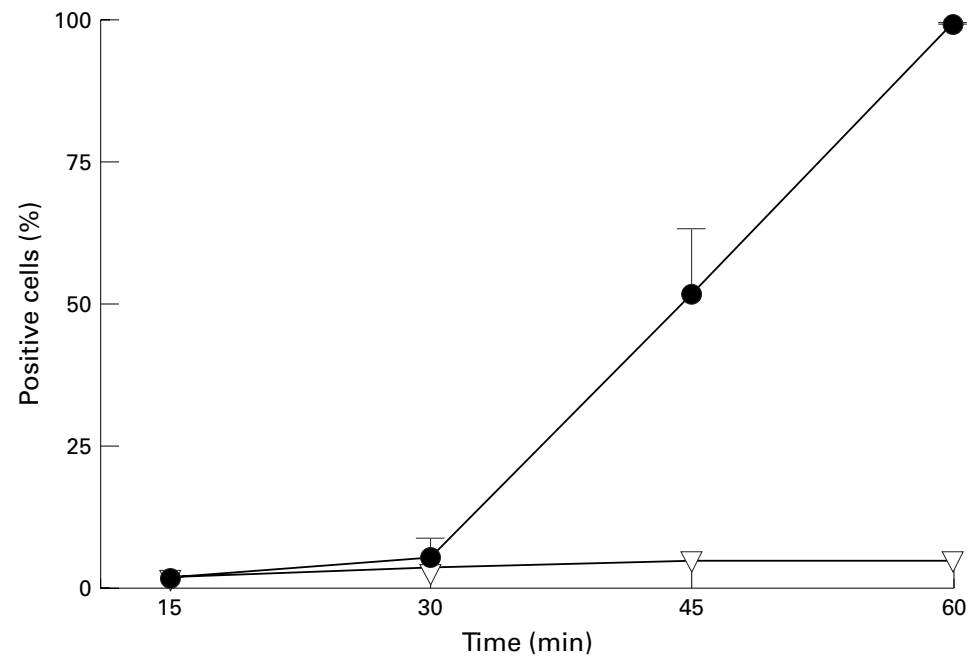

Figure 2 The effect of proteinase Kon the outcome of the TUNEL assay without pretreatment (closed circle) and after DEPC pretreatment (open triangle) of liver tissue slides. Positive nuclei were quantified stereologically; mean (SD) values are given.

To inhibit interfering enzyme activities, after dewaxing, the slides were incubated in an ethanolic solution of diethyl pyrocarbonate (DEPC; $4 \% \mathrm{vol} / \mathrm{vol}$ ) for 30 minutes at $4^{\circ} \mathrm{C}$, after which the procedure described above was carried out. In another set of experiments, digestion was carried out with pepsin $(0.5 \%$ $\mathrm{wt} / \mathrm{vol})$ in $\mathrm{HCl}(0.1 \mathrm{mmol} / \mathrm{l})$ and $\mathrm{NaCl}$ $(0.1 \mathrm{mmoles} / \mathrm{l})$ instead of proteinase $\mathrm{K}$.

As a positive control, DNA nicks were induced by incubation of the slides with DNAase I (Boehringer Mannheim), as proposed by Wijsman et al. ${ }^{9}$ After digestion with proteinase $\mathrm{K}$, the slides were washed twice with Tris/ $\mathrm{HCl}(10 \mathrm{mmol} / \mathrm{l}, \mathrm{pH} 8.1)$ in $150 \mathrm{mmol} / 1$ $\mathrm{NaCl}$, and then incubated with DNAase I $(0.2 \mu \mathrm{g} / \mathrm{ml})$ in Tris $/ \mathrm{HCl}(10 \mathrm{mmol} / \mathrm{l}, \mathrm{pH} 7.4)$ containing $\mathrm{NaCl}(10 \mathrm{mmol} / \mathrm{l}), \mathrm{MgCl}_{2}(5 \mathrm{mmol} /$ 1), $\mathrm{CaCl}_{2}(0.1 \mathrm{mmol} / \mathrm{l})$, and $\mathrm{KCl}(25 \mathrm{mmol} / \mathrm{l})$ for 15 minutes at $37^{\circ} \mathrm{C}$. Further processing was as described above.

\section{ENDOGENOUS NUCLEASE ACTIVITY}

DNA digestion by proteinase $\mathrm{K}$ and endogenous endonucleases was assessed as follows: untreated tissue slides and slides pretreated with DEPC were incubated for 24 hours at $37^{\circ} \mathrm{C}$ with Tris/EDTA buffer containing genomic DNA $(1 \mu \mathrm{g} / \mathrm{ml})$ and proteinase $\mathrm{K}$ $(10 \mu \mathrm{g} / \mathrm{ml})$. Control slides were incubated under the same conditions with DNA alone. To assess whether proteinase $\mathrm{K}$ had DNAse activity, it was incubated with DNA under similar conditions but without exposure to tissue. After incubation, $200 \mu \mathrm{l}$ of the incubation solution was used for extraction of DNA. DNA extraction was performed with phenol/ chloroform and precipitation was performed with ethanol. ${ }^{10}$ DNA was then dissolved in Tris/EDTA buffer (10 mM Tris- $\mathrm{HCl}, 1 \mathrm{mM}$ EDTA, pH 7.5). Aliquots $(1 \mu \mathrm{g})$ of DNA were characterised by electrophoresis in a $0.8 \%$ agarose gel containing Tris/borate/EDTA buffer and ethidium bromide. Gels were run at $100 \mathrm{~V}$ for 45 minutes and were then photographed under UV light.

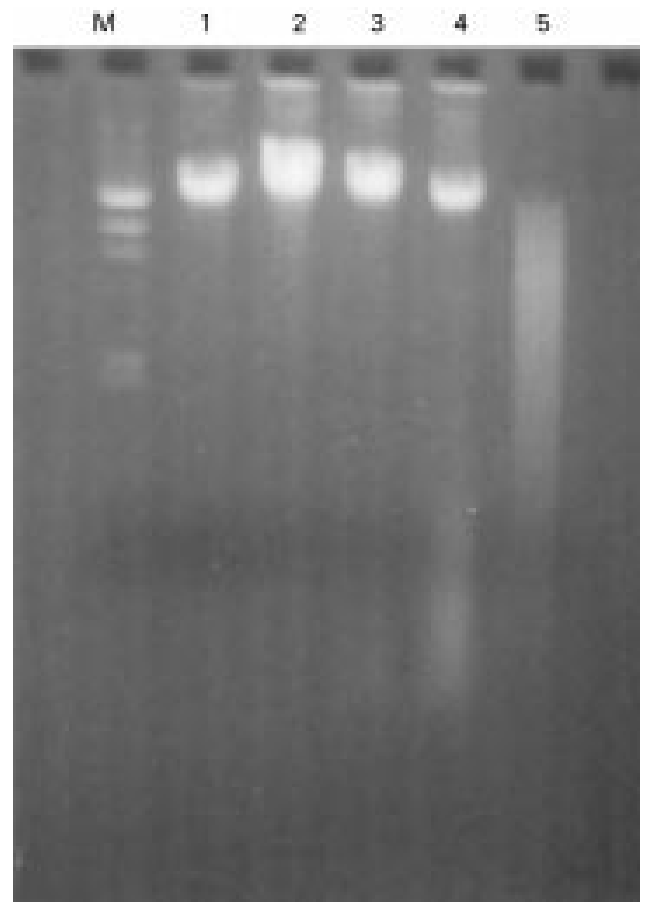

Figure 3 DNA digestion assay. Lane 1, genomic human DNA without an incubation step; lane 2, DNA incubated for 12 hours with proteinase Kat $37^{\circ} \mathrm{C}$; lane 3, DNA incubated on liver tissue slides for 12 hours without proteinase K; lane 4, $D N A$ after DEPC pretreatment with proteinase K; lane 5, $D N A$ without DEPC pretreatment in the presence of proteinase K; lane $M$, molecular weight markers.

DATA AND STATISTICAL ANALYSIS

The volume fraction of TUNEL positive cells was quantified by a point counting procedure ${ }^{11}$ as described previously. ${ }^{5}$ TUNEL positive cells were counted similarly and related to the volume fraction of the cell population under consideration (bile duct epithelial cells). Results are reported as mean (standard deviation (SD)). Mean values from different groups were compared by analysis of variance. ${ }^{12}$

\section{Results}

In control liver, less than one in 1000 cells exhibited features of apoptosis in haematoxylin and eosin stained sections using the criteria of Kerr. ${ }^{13}$ In contrast, using the standard TUNEL assay, up to $20 \%$ of cells stained positive, most of them in the absence of related morphological features of apoptosis, in particular condensation of chromatin at the nuclear membrane (fig 1A).

Different factors that could be responsible for this false positive staining were investigated. Replacing proteinase $\mathrm{K}$ with pepsin as proposed by Wijsman and colleagues ${ }^{9}$ gave identical results. Performing a time course of incubation with proteinase $\mathrm{K}$ showed no positive cells with an incubation of up to 30 minutes; thereafter, there was a linear increase in cell positivity, with all cells becoming positive after 45 minutes. However, the percentage of positive cells varied greatly from one batch to another, making standardisation of proteinase $\mathrm{K}$ treatment impossible (fig 2).

This non-specific DNA degradation was not caused by proteinase $\mathrm{K}$ because incubation of DNA with proteinase $\mathrm{K}$ did not induce DNA 
Evolution of TUNEL positive bile duct epithelial cells after biliary decompression in rats with ligation/dissection of the common bile duct

\begin{tabular}{lc}
\hline Time after surgery (days) & TUNEL positive cells (\%) \\
\hline 0 & $<0.1$ \\
1 & $5.4(1.5)^{\star}$ \\
2 & $1.3(1.1)^{\star}$ \\
3 & $3.5(4.4)^{\star}$ \\
7 & $<0.1$
\end{tabular}

Results (mean (SD)) were analysed by analysis of variance compared to day 0 .

$\star$ Significant difference $(\mathrm{p}<0.05)$.

degradation (fig 3). In contrast, there was some spontaneous DNA degradation when DNA was incubated with tissue sections pretreated or not with DEPC (fig 3). When the complete procedure including proteinase $\mathrm{K}$ treatment was performed on pretreated and untreated tissue sections, it became evident that DEPC almost completely inhibited DNA degradation by these putative endogenous endonucleases (fig 3).

Therefore, the TUNEL procedure was modified by inclusion of an inactivation step with DEPC as described in the methods section. Mounting the sections with cement proved to be crucial because silanised slides (which are often used in in situ hybridisation) prevented the inactivating effect of DEPC (data not shown). Pre-incubation of the slides with DEPC abolished the false positive staining completely: only cells with clear features of apoptosis stained positive in the TUNEL assay (fig 1B). Accordingly, stereological analysis of the involution of bile duct epithelial cells was parallelled by a wave of apoptosis (table 1 ).

Even more rewarding is the fact that DEPC pretreatment eliminated false positive staining in necrosis (fig 1C) induced by acute $\mathrm{CCl}_{4}$ intoxication (fig 1D), in contrast to the conventional TUNEL assay reported by GraslKraupp et al. ${ }^{3}$

In addition, in the intestine, there were many false positive cells and a strong reaction caused by the endogenous alkaline phosphatase of the brush border (fig 1E), which was eliminated by pretreatment with DEPC (figure $1 \mathrm{~F}$ ). However, thymus and mammary gland were found to be insensitive to DEPC pretreatment (data not shown).

\section{Discussion}

Apoptosis is a common mode of cell death in different liver diseases. ${ }^{14}$ DNA laddering is considered to be the hallmark of apoptosis ${ }^{15}$ and it is detected most reliably by gel electrophoresis, where a characteristic laddering pattern is seen, which results from cleavage of DNA into strands of about 200 kilo bases in length. ${ }^{16}$ Even though it occurs late in the process, it is considered to be one, if not the most, valuable feature for the detection of cell death by apoptosis ${ }^{14} 17$; however, it cannot be demonstrated in all experimental settings. ${ }^{19}$ Furthermore, the method cannot be applied to archival, paraffin wax embedded material. Therefore, the TUNEL assay developed by Gavrieli and colleagues $^{2}$ is widely used because it permits in situ visualisation of DNA cleavage by inserting a marker at the 3' nick end. The lack of specifi- city of the method is obvious because terminal transferase (the enzyme used to perform the nick end labelling) will recognise any 3 ' nick ends, regardless of their origin. This is because unlike all other DNA polymerases, terminal deoxyribonucleotidyl transferase does not require template instruction for polymerisation. ${ }^{20}$ This is exemplified by the study of GraslKraupp et al, who were unable to differentiate between necrotic, autolytic, or apoptotic cell death using the TUNEL assay. ${ }^{3}$

In attempting to quantify apoptotic bodies with the TUNEL assay, we found that proteinase $\mathrm{K}$ digestion - introduced into the assay to make cleaved DNA accessible to the terminal transferase-induced a rapid increase in positive nuclei and that this step could not be controlled reproducibly. This has been noted previously by another group of investigators. ${ }^{9}$ According to their suggestion, we replaced proteinase $\mathrm{K}$ with pepsin; this did not abolish false positive staining, suggesting that, at least in liver, there is a general effect of proteases on the outcome of the TUNEL assay, perhaps related to the release of endogenous endonucleases. It is known that the secondary structure of proteins remains unchanged after formaldehyde fixation ${ }^{21}$ and alkaline phosphatase remains active in formalin fixed tissue (fig 1E). Therefore, we attempted to inhibit such putative endonucleases by pretreatment of the histology slides with DEPC, a nonspecific inhibitor of DNAases and RNAases commonly used in molecular biology. DEPC pretreatment abolished the false positive staining-positive cells all exhibited the morphological features of apoptosis. Moreover, DEPC pretreatment also abolished the false positive staining in necrosis induced by $\mathrm{CCl}_{4}$, suggesting that the proposed modification might be able to overcome the lack of specificity of the TUNEL assay.

It is of interest that not all tissues were vulnerable to proteinase digestion. In the intestine there was false positive nuclear staining and a strong reaction of endogenous alkaline phosphatase with the chromogen; both reactions were abolished by DEPC treatment. In contrast, neither thymus nor involuting mammary gland showed a false positive TUNEL reaction, which might be related to varying amounts of the putative endogenous endonucleases in different organs.

DEPC did not affect the accessibility of nuclear DNA to the terminal transferase as shown by positive staining of all nuclei in tissue sections treated with DNAse, which should be included as a positive control. ${ }^{9}$ Finally, it should be noted that the method of gluing the tissue section to the glass slide is of utmost importance and that in particular the effect of DEPC is abolished on silanised slides.

Bile duct ligation in the rat induces marked ductular proliferation, ${ }^{45}$ which (in addition to the associated fibrosis) is reversible after biliary decompression. ${ }^{6}$ The hyperplastic bile duct epithelial cells are removed by apoptosis, as demonstrated morphologically by Bhathal et $a l .{ }^{7}$ The data in table 1 confirm and quantitate this finding, showing that there is a rapid wave 
of TUNEL positive cells leading to removal of most bile duct epithelial cells within a week.

We conclude that the inclusion of an incubation step with DEPC inactivates endogenous endonucleases that can give false positive results in the TUNEL assay in liver and intestine. This step also should allow a better differentiation between death by necrosis and apoptosis.

Supported by a grant from the Swiss National Foundation for Scientific Research (No. 32.45349.95) to JR.

1 Que FG, Gores GJ. Cell death by apoptosis: basic concepts and disease relevance for the gastroenterologist. Gastroenand disease relevance for the

2 Gavrieli Y, Sherman Y, Ben-Sasson SA. Identification of programmed cell death in situ via specific labelling of nuclear DNA fragmentation. F Cell Biol 1992;119:493501.

3 Grasi-Kraupp B, Ruttkay-Nedecky B, Koudelka H, et al. In situ detection of fragmented DNA (TUNEL assay) fails to discriminate among apoptosis, necrosis, and autolytic cell death: a cautionary note. Hepatology 1995;21:1465-8.

4 Kontouras J, Billing BH, Scheuer PJ. Prolonged bile duct obstruction: a new experimental model for cirrhosis in the rat. Br F Exp Pathol 1984;65:305-11.

5 Gross JB, Reichen J, Zeltner T, et al. The evolution of changes in quantitative liver function tests in a rat model of cirrhosis: correlation with morphometric measurement of hepatocyte mass. Hepatology 1987;7:457-63.

6 Zimmermann H, Reichen J, Zimmermann A, et al. Reversibility of secondary biliary fibrosis by biliodigestive anastomosis in the rat. Gastroenterology 1992;103:579-89.
7 Bhathal PS, Gall JAM. Deletion of hyperplastic biliary epithelial cells by apoptosis following removal of the proliferathelial cells by apoptosis following rem
tive stimulus. Liver 1985;5:311-25.

8 Cruz-Orive LM, Weibel ER. Sampling design for stereology. f Microsc 1981;122:235-7.

9 Wijsman JH, Jonker RR, Keijzer R, et al. A new method to detect apoptosis in paraffin sections: in situ end labeling for fragmented DNA. F Histochem Cytochem 1993;41:7-12.

10 Anonymous. Short protocols in molecular biology. New York: John Wiley and Sons, 1992.

11 Weibel ER. Stereological methods. London: Academic Press, 1979.

12 Snedecor GW, Cochran WG. Statistical methods. Iowa: Iowa State University Press, 1967.

13 Kerr JFR Shrinkage necrosis: a distinct mode of cellular death. F Pathol 1971;105:13-20.

14 Patel T, Gores GJ. Apoptosis and hepatobiliary disease. Hepatology 1995;21:1725-41.

15 Alles A, Alley K, Barrett JC, et al. Apoptosis: a general comment. FASEB f 1991;5:2127-8.

16 Wyllie AH. Glucocorticoid induced thymocyte apoptosis is associated with endogeneous endonuclease activation. Nature 1980;284:555-6.

17 Raff MC. Social control on cell survival and cell death. Nature 1992;356:397-9.

18 Williams GT, Smith C. Molecular regulation of apoptosis: genetic control of cell death. Cell 1993;74:777-9.

19 Oberhammer F, Bursch W, Tiefenbacher R, et al. Apoptosis is induced by transforming growth factor $\beta_{1}$ within 5 hours in regressing liver without significant fragmentation of the DNA. Hepatology 1993;18:1238-46.

20 Gorczyca W, Gong J, Darzynkiewicz Z. Detection of DNA strand breaks in individual apoptotic cells by in situ terminal deoxyribonucleotidyl transferase and nick translation assay. Cancer Res 1993;53:1945-51.

21 Mason JT, O'Leary TJ. Effects of formaldehyde fixation on protein secondary structure: a calorimetric and infrared spectroscopic investigation. F Histochem Cytochem 1991;39: $225-9$. 